\title{
Testing for external sustainability under a monetary integration process. Does the Lawson doctrine apply to Europe?
}

\author{
Mariam Camarero \\ Jaume I University \\ Josep Lluís Carrion-i-Silvestre \\ University of Barcelona \\ Cecilio Tamarit ${ }^{1}$ \\ University of Valencia
}

January 2014

\begin{abstract}
Monetary integration, and more specifically, the creation of a monetary union in Europe, raises new economic questions concerning its functioning and governance. In particular, we focus on the implications of high and persistent current account deficits for the economic performance of monetary union members in the medium term. Recent literature has argued that conventional measures of external sustainability are misleading because they omit the effects of capital variations on net foreign asset positions due to, among others, stock or debt market crises. In this paper we revisit external sustainability making use of the database developed by Lane and Milesi-Ferretti (2007) that includes these "valuation effects". The sample period studied covers from the launching of the monetary integration process in Europe (the creation of the European Snake in 1972) up to 2011. Our econometric methodology accounts for the increasing cross-section dependence among EMU countries as well as for possible structural breaks endogenously determined. The results point to the need of abrupt adjustments, either led by the markets or promoted by pro-active policy measures, in order to offset external disequilibria. These results would give support to the surveillance measures proposed by the European Commission $(2009,2010 a)$ and would reject the Lawson's doctrine of "laissez-faire".
\end{abstract}

Keywords: Current account imbalances, EMU, panel stationarity, structural breaks, cross-section dependence

JEL codes: F32, F41, C23

1 Corresponding author: Department of Applied Economics II, University of Valencia, PO Box 22006, E46071 Valencia (Spain). Phone: +34963828349. Fax: +34963828354. e-mail: cecilio.tamarit@uv.es; http://www.uv.es/ tamac 


\section{Introduction}

A monetary union raises new economic questions about the interpretation and the implications of large current account deficits for its members in terms of macroeconomic stability. In fact, according to Mayer (2011), below the surface of the current euro area public debt and banking crisis lays a balance-of-payments crisis caused by a misalignment of internal real exchange rates.

A country's current account balance is the usual indicator of the external equilibrium of the economy, as it measures its net borrowing requirement or net lending capacity and is equivalent to the difference between aggregate saving and aggregate investment. Therefore, current account imbalances in a set of heterogeneous countries are a normal occurrence. The countries with the highest growth rates, either due to productivity or demographic differences, or just with a greater structural preference for the present, will run current account deficits in the medium term. According to this approach, the external constraint can be interpreted as a long-term issue and not on a year-by-year basis. Blanchard (2007) showed that deficits reflect rational private saving and investment decisions. In the case of the European Monetary Union (EMU hereafter), foreign borrowing would be the outcome of an intertemporal consumption smoothing approach in a catching-up process where the Southern peripheral countries would generate productivity gains to service the increasing debt. Therefore, there is no reason for government intervention, the socalled "Lawson doctrine". ${ }^{2}$ In accordance with this view, during the first decade of the EMU, European authorities treated current account imbalances with benign neglect. However, since the financial crisis started in 2008, the approach has changed dramatically and has turned to a new one increasingly focused on the sustainability of the persistent trade deficits and the accumulation of foreign debt. ${ }^{3}$ Alternatively, according to the "prudential IMF view", if nominal rigidities and market distortions are present, deficit may become "excessive" and government interventions are needed. As for the EMU case, the European Commission (2009, 2010a) claims that the gap in potential growth between euro area countries only partially explains the dispersion of the current account imbalances in the Eurozone during the last decade. In fact, the European authorities have recognized by now that there existed an important problem of macroeconomic governance in the monetary union. According to European Commission (2012), persistent macroeconomic imbalances, reflected in large and persistent external deficits and surpluses, sustained losses in competitiveness, and the build-up of indebtedness, have been part

\footnotetext{
2 The "Lawson doctrine", named after Nigel Lawson, the Chancellor of the Exchequer, who articulated it in the 1980s. This "doctrine" is basically a restatement of the first welfare theorem: "To the extent that current account deficits involve private saving and investment decisions, that there are no distortions, and that expectations are rational, then there are no reasons for the government to intervene."

${ }^{3}$ see Giavazzi and Spaventa (2010) and Holinsky, et al. (2012),
} 
at the core of the economic crisis. Moreover, they continue to frame the macroeconomic challenges for the Member States concerned and involve spillovers which contribute to the threats facing the euro area. In 2013 some changes were adopted, such as the entry into force of a reinforced Stability and Growth Pact (SGP) and a new Macroeconomic Imbalance Procedure (MIP). ${ }^{4}$ The MIP is a surveillance mechanism that aims to identify potential risks at an early stage. This mechanism is based on a scoreboard of indicators that include, among them, the current account balance and the NFA position. Until the launching of the MIP, external imbalances of the euro-area members had attracted little attention, partly because the Eurozone as a whole had a relatively balanced current account and because, in the past, any structural balance of payments crisis was solved via realignments (under an adjustable peg system) in the Exchange Rate Mechanism of the European Monetary System. Some economists, like Sinn (2013) or Ji and De Grauwe (2013), from different point of views, interpret the present Euro crisis as a crisis of a fixed exchange rate regime: as long as deficits are balanced by capital inflows, the currency board would be sustainable, but when these flows come to a "sudden stop", the system risks breaking up. The negative values of the net foreign assets (NFA) position reflect the accumulated effect of persistent current account deficits, and, therefore, the imbalance between foreign assets and liabilities. Many converging countries benefited from the high degree of financial integration and were able to finance their growing imbalances through foreign capital entries. However, the deterioration of the NFA position was so severe in many cases that called for further adjustments. The theoretical literature ${ }^{5}$ has outlined three types of market adjustment mechanisms that can promote, either separately or jointly, a return to equilibrium in a monetary union: first, price adjustment (wages and prices in tradable and non-tradable sectors), second, migration, ${ }^{6}$ and third, financial adjustment. According to Ingram (1959), the higher the degree of financial integration, the lower the need for exchange rate changes among partner countries, because changes in interest rates would provoke compensating capital flows across national frontiers. Moreover, to avoid an over-costly adjustment when the current account deficit becomes too high, it may be preferable to use certain economic policy levers rather than let the adjustment occur spontaneously. From a macroeconomic point of view, in the ideal world of the Optimum Currency Areas (OCA) the economic consequences of an asymmetric shock hitting different countries of a monetary union should be adsorbed through a centralized budget. However, in the real world, such as in a monetary union among countries with decentralized national budgets,

4 See http://ec.europa.eu/economy_finance/economic_governance/macroeconomic_imbalance_procedure/index _ en.htm for more details.

${ }_{5}^{5}$ See, for instance, De Grauwe (2009).

${ }^{6}$ In European Commission (2008b) the econometric evidence backs the idea of a link between labour market flexibility and competitiveness adjustment. 
when one country is negatively affected by a shock, the OCA theory advises the flexible use of fiscal policies. That means that the public deficit should be allowed to increase and automatic stabilizers must come freely into play. Its neighbors with surplus savings can finance this country's deficit and debt as long as the capital markets are efficient and frictionless. However, the transfer of savings is not free, as the country in difficulties will have to pay the service of its debt (interest and principal). The rapid accumulation of public debt puts upward pressure on real long-term interest rates, which acts as a deadweight for growth. Therefore, the economic literature points out that for a monetary union to function properly, fiscal rules must be put in place. This was the rational of the convergence rules under the Maastricht Treaty and the Stability and Growth Pact. However, the current crisis has shown that their design had important shortcomings.

As we are currently aware, the limits to the financial adjustment mechanism apply jointly to the degree of private and public leverage. Several euro Member States face deleveraging pressures in the private and public sector nowadays. These pressures reflect the unwinding of accumulated financial imbalances, which are linked to previous unsustainable expenditure and debt levels.

Although the financial adjustment mechanism becomes especially important in a monetary union, it has been mostly neglected both by academics and politicians. ${ }^{7}$ As we have already pointed out, in a monetary union the sustainability of certain paths for net external positions can theoretically be restored through financial channels. Although, in principle, the notion of country risk is less relevant in a monetary union, financial crises may trigger episodes of sovereign debt crisis. In a monetary union a loss of investors' confidence will not entail an abrupt devaluation (as under a flexible rate regime) but will drive up risk premia. This is exactly what happened to the peripheral countries of the Eurozone causing a "de facto" asymmetric shock. It is important to stress at this point that this financial adjustment can be more painful than currency devaluation because it would restore sustainability by lowering domestic demand rather than boosting foreign demand. Moreover, higher external debt will ultimately result in future spending cuts or a future rise in domestic taxes, a burden mostly shouldered by resident agents (Schnabl and Zemanek, 2011). In the case of the EMU crisis, the simultaneous deleveraging of private and public sectors is weighing on growth, as spending is reduced and income is directed to debt repayment, while the correction of the external deficits, to be complete and sustainable, requires further improvement in relative competitiveness, including through the reductions in costs and increases in productivity. This adjustment of accumulated internal and external imbalances is expected to be a protracted process shaping the economic landscape for several years to come

7 Before the crisis, the mainstream position adopted by the European authorities was to abandon implicit policies targeting current account balances. In fact, from the early stages of the design of EMU, the prevailing idea was that the balance of payments' constraint of member countries would largely disappear. 
and framing the surveillance under the MIP. This is at odds with the alternative approach according to which the elimination of currency risk and the wider and deeper financial markets would facilitate the financing of external deficits. Consequently, the adjustment (if necessary) would be made smoothly by the market itself, as stated by the so-called Lawson doctrine.

Therefore, the aim of this research is twofold. First, we empirically test for long-term solvency and sustainability of the current account deficits for the EMU countries. Second, we test for the validity of the Lawson doctrine as an indirect outcome of our study. The contribution of our paper is that, conversely to the traditional approach that focused on the trade adjustment channel, we analyze NFA behavior based on the financial channel. Gourinchas and Rey (2007) argued that conventional measures of external sustainability - the trade balance and the current account - are misleading because they omit capital gains or losses on net foreign asset positions. ${ }^{8}$ In this paper we analyze external sustainability making use of the most updated version of the database created by Lane and Milesi-Ferretti (2007) that includes valuation effects. The sample period studied covers from 1972, namely the creation of the European Snake, up to 2011. The econometric methodology accounts for the increasing cross-section dependence among EMU countries as well as for possible structural breaks endogenously determined.

The reminder of the paper is organized as follows. Section 2 displays a short revision of the previous empirical literature and discusses the theoretical framework that guides our empirical investigation. Section 3 presents succinctly the econometric methodology and the empirical results and, finally, Section 4 concludes with some policy discussion.

\section{Testing for external sustainability: empirical and theoretical issues}

In this paper we propose testing for sustainability and solvency of the current account following the distinction made by Milesi-Ferretti and Razin (1996) focusing on the "financial adjustment mechanism" as coined by Gourinchas and Rey (2007). We distinguish between the concepts of sustainability and solvency. First, we test for external sustainability as the ability of an economy to meet its intertemporal external constraint in the long term excluding potential discontinuities. As Trehan and Walsh (1991) pointed out, the I(0) stationarity of the current account is a sufficient condition to ensure compliance with the intertemporal budget constraint. This can be tested easily through the application of unit root and stationarity tests. However, it must be borne in mind that we are working in a context of expected values of future events; therefore, changes in the agents' perceptions on different factors - as the risk, the decisions on portfolio asset composition, economic policy variations, or changes in the transaction costs in international

\footnotetext{
${ }^{9}$ See also Gourinchas and Rey (2013) for a survey.
} 
financial markets, among others - can lead to variations or structural breaks that trigger the dynamic adjustment to the current account equilibrium. Therefore, in a second step, we test for solvency accounting for possible abrupt adjustments in the time series.

Besides, a second feature of our research is the use of stock variables instead of flows. Many investigations that measure the dynamics of the adjustment process are still based on flows - for example, Bussière et al. (2004) and Zanghieri (2004). This approach has a major problem, namely to ignore the changes in valuation of foreign assets and liabilities. A stock approach can successfully solve this problem. Further, stocks are less volatile and can provide a long-term relationship that might be easier to estimate. Successful examples of this approach are Calderon et al. (2000, 2002), Lane and Milesi-Ferretti (2007) and the IMF (2005). Particularly remarkable is the contribution of Gourinchas and Rey (2007) that used monthly data in an intertemporal budget constraint approach to the assessment of US external imbalances.

From an econometric point of view, the literature on sustainability of the current account can be split into two alternative approaches. A first approach uses a time series analysis to study the long-term relationship between exports and imports or the $\mathrm{I}(0)$ stationarity of the accumulation process of external debt - see Chortareas et al. (2004). With the exception of Liu and Tanner (1996), who consider the existence of structural changes, the general finding is that the relations are not stationary for the major industrialized countries including the US, UK, Canada, Germany and Japan. A second approach has applied panel data unit root tests to improve the statistical inference that is obtained using individual tests - see $\mathrm{Wu}$ (2000), Wu et al. (2001) and Holmes (2006), among others.

Another additional problem is the presence of cross-section dependence, which can invalidate the inference. This kind of dependence is a common feature in economic integrated areas such as the eurozone. Therefore it is highly convenient to take cross-section dependence into account in the analysis of the external imbalances as in Brissimis et al. $(2010,2013)$.

In this paper we empirically test the sustainability of the current account, adding to the previous literature from different perspectives. First, we pay special attention to an alternative key condition for the validity of the external sustainability, i.e., the $\mathrm{I}(0)$ stationarity of the stock of net foreign asset position to GDP ratio $(n f a)$. Secondly, the use of the updated database developed by Lane and Milesi-Ferretti (2007) allows the implementation of the stock market value approach for outstanding amounts of foreign assets in contrast to the flow approach at historical prices. Thirdly, we discuss the application of sustainability tests through the use of non-stationary panel data analysis. We propose the application of a class of panel data test statistics that allows for the existence of cross-section dependence and structural breaks in the time dimension of the panel.

From an econometric point of view the contribution of this paper is twofold. First, we test for the 
presence of structural breaks affecting the $n f a$ time series, considering as a particular case the situation with no structural breaks. Once the presence of structural breaks has been investigated, then individual stationarity test statistics are computed. Second, such individual tests can be pooled to define panel-data-based test statistics, which permit an assessment of the $n f a$ stochastic properties using more powerful statistical tools. The statistical inference is conducted taking into account the presence of cross-section dependence through the computation of the bootstrap distribution and the use of common factor models.

The theoretical underpinnings of our testing relationship draw on the model developed in Gourinchas and Rey (2007). They start from a country's intertemporal budget constraint that links the net foreign asset position and the future dynamics of the current account.

The value of foreign assets owned by domestic residents $(A)$ minus the value of domestic liabilities to the rest of the world $(L)$ is called the national NFA position. If its net foreign asset position is positive $(N F A>0)$, the country is a net creditor to the rest of the world. Conversely, if NFA is negative $(N F A<0)$ then the country is a net debtor. Combining this relationship with the definition of the current account, it follows that the change in the net foreign assets position is the current account balance:

$$
N X_{t}+N F I_{t}+U T_{t}=C A_{t}=N F A_{t}-N F A_{t-1},
$$

which implies that the change in the net foreign asset position is the sum of net exports $\left(N X_{t}\right)$, net foreign income $\left(N F I_{t}\right)$, and unilateral transfers $\left(U T_{t}\right)$, i.e., the current account balance. Therefore, the current account represents the rate at which a country accumulates or reduces foreign assets.

In order to derive the different testing hypotheses, let us consider the accumulation identity for net foreign assets between $t$ and $t-1$ :

$$
N F A_{t}=\left(1+r_{t}\right) N F A_{t-1}+C A_{t}
$$

The IMF (2005) has proposed two methodologies based on an estimated "benchmark" equilibrium current account, namely, the so-called current account norm (CAN) approach and the net foreign asset stabilization (NFAS) approach. The difference between the two approaches lies in the notion of the equilibrium current account used. In the CAN approach, the current account that would prevail over the medium-to-long term is estimated on the basis of fundamentals related to a balance of the economy, ${ }^{9}$ while in the NFAS approach, the benchmark current account is the one that guarantees the stabilization of the NFA/GDP ratio at its current

${ }^{9}$ See Chinn and Prasad (2003) or Lee et al (2008). 
level.

To make this approach operational, researchers typically assume that the economy targets a given debt-to-GDP ratio $\left(n f a^{*}\right)$, and consider the particular case in which current policy would remain unchanged into the indefinite future (Corsetti and Roubini, 1991). Such applications are also referred to as the External Sustainability Approach. ${ }^{10}$ In practical terms, the arithmetic of sustainability examines whether the net debt to GDP ratio grows more or less rapidly than the difference between the real interest rate and the economy's growth rate.

Following Chortareas et al. (2004), equation (2) can be rewritten dividing by GDP all the variables and taking $n f a_{t-1}$ from both sides of the equation:

$$
\Delta n f a_{t} \cong c a_{t}+\tilde{r}_{t} n f a_{t-1},
$$

where $\tilde{r}_{t}=r_{t}-\dot{p}_{t}-\dot{y}_{t}$ is the growth-adjusted real return on net foreign debt, $\dot{p}_{t}=\Delta \log P_{t}$ and $\dot{y}_{t}=\Delta \log Y_{t}$. Assuming $\tilde{r}_{t}>0$, solving (3) forward, and imposing the no-Ponzi game condition, the Intertemporal Budget Constraint is:

$$
n f a_{t}=-\sum_{j=1}^{n} \rho_{t} c a_{t+j},
$$

with $\rho_{t}=\Pi_{s=1}^{n}\left(1+\tilde{r}_{t+s}\right)^{-1}$. If this condition holds, current and future discounted primary current account surpluses are sufficient to pay off initial indebtedness. Therefore, a test for external sustainability can rely on the use of unit root and stationarity tests to determine the order of integration of $n f a_{t}$. According to the previous condition, we will say that an economy shows external sustainability when $\mathrm{I}(0)$ stationarity is found without breaks (abrupt changes) in the $n f a_{t}$ , so that sustainability does not require the adoption of policy measures or interventions to correct the deviations. Besides, we will conclude that an economy is only externally solvent when the variable is found to be $I(0)$ once structural breaks have been accounted for, since these structural breaks can reflect the effect of policy interventions aimed at controlling the debt. In case the variable is found to be I(1) non-stationary, that would be pointing to the need of a future external adjustment to become solvent. ${ }^{11}$

\footnotetext{
10 See Isard (2007).

${ }^{11}$ Note that the $\mathrm{I}(0)$ stationarity of $n f a_{t}$ is a sufficient condition for sustainability. However, Bohn (2007) claimed in the context of public finance, that public debt can have a higher order of integration provided that a cointegration relationship between the primary deficit (trade deficit) and debt $\left(n f a_{t}\right)$ exists and he calls for an analysis of the fiscal reaction function. Although in our context the aforementioned analysis of the relationship between trade deficit and $n f a_{t}$ is beyond the scope of this paper, the intuition behind the
} 


\section{Econometric methodology and results}

In this section we present the testing strategy that we use to address the theoretical issues described above. The empirical application is based on a panel data set that consists of 11 EMU countries (Austria, Belgium, Finland, France, Germany, Greece, Ireland, Italy, Netherlands, Portugal and Spain). The sample covers the period 1972-2011, and the data has been obtained from the World Bank and the newest version of the External Wealth of Nations Mark II (EWN II) database provided by Lane and Milesi-Ferretti (2007). The variable of interest is the net foreign asset stock as a percentage of GDP $\left(n f a_{i, t}\right)$. The EWN II database has been elaborated accounting for valuation effects on the stocks of foreign assets and liabilities. ${ }^{12}$ We test for the sustainability of net foreign assets position for our group of countries using non-stationary panel data methods. We have applied panel data based statistics following a two-step testing strategy that addresses the problems related to the issues of multiple structural breaks and cross-section dependence. ${ }^{13}$

\subsection{Testing for the presence of multiple structural breaks}

The first stage of our analysis consists of assessing the presence of structural breaks affecting the $n f a_{i, t}$ time series using the following specification:

$$
n f a_{i, t}=\alpha_{i}+\beta_{i} t+\sum_{k=1}^{m_{i}} \theta_{i, k} D U_{i, k, t}+\sum_{k=1}^{m_{i}} \gamma_{i, k} D T_{i, k, t}+e_{i, t},
$$

$t=1, \ldots, T, i=1, \ldots, N$, with $D U_{i, k, t}=1$ and $D T_{i, k, t}=\left(t-T_{b, k}^{i}\right)$ for $t>T_{b, k}^{i}$ and 0 elsewhere $T_{b, k}^{i}$ denotes the $k$-th break point for the $i$-th individual, $k=1, \ldots, m_{i}$ - and where $\left\{e_{i, t}\right\}$ is assumed to be an $\mathrm{I}(0)$ stationary process. This specification is based on the use of a time trend, which captures the trending pattern of the variables that we analyze - see Figure 1. Both the level and the slope of the trend might have been affected by the presence of structural breaks. Further, the specification permits a high degree of heterogeneity assuming that the structural breaks may have different effects on each individual time series. We argue that there are several reasons to

structural breaks found in $n f a_{t}$ is that these changes are the result of adjustments in the trade deficit, which are required to correct unsustainable trajectories.

${ }^{12}$ According to Lane and Milesi-Ferretti (2007) and Gourinchas and Rey(2013), the size of countries' external portfolios is now such that fluctuations in exchange rates and asset prices (or debt interest rate premia) cause very significant reallocations of wealth across countries.

13 We have applied as well classical panel unit root and stationarity tests without structural breaks finding mixed results. These results are available from the authors upon request. 
believe that these variables may suffer from discontinuities. Previous evidence has revealed that there might be some events that affect the external debt in a permanent way. For this purpose, the analysis that we carry out allows the break points to be located at different dates for each country, and the countries may have different number of structural breaks. Under these conditions, we will use the procedure proposed by Bai and Perron (1998) for the estimation of the number and position of the structural breaks. When computing the statistic we have to specify a maximum number of structural breaks, which in this case has been set equal to $m_{i}=3 \forall i$ given the number of time observations that is available. The number of structural breaks is estimated using the Liu-Wu-Zidek (LWZ) information criterion, as suggested in Bai and Perron (1998).

Panel A in Table 1 reports the estimated number and position of the structural breaks for each country. We can see that the procedure detects at least one structural break for each time series. This evidence may suggest that previous empirical analyses that do not account for the presence of structural breaks may have omitted relevant information.

The picture that emerges from these results is that until the beginning of the nineties countries with a negative NFA position were able, after a structural break, to reverse or at least correct that position. These are the cases of Belgium, Ireland or Portugal in the eighties. Free capital mobility has made possible to finance persistent disequilibria in the peripheral countries (in particular, Greece, Spain, Portugal and Italy). In contrast, Finland worsened its position at the end of the nineties (due to the URSS decomposition) but came back to equilibrium around 2004 and improved afterwards. This was also the case of the Netherlands in 2002.

The different exchange rate regimes along these periods, together with divergent competitiveness paths across member countries, have caused several external crises episodes followed inexorably by adjustments originated either by market forces or policy measures. The new framework established by the monetary union led economists to think that the external constraint was not playing an important role anymore. In this new environment, the price competitiveness adjustment channel, being still important, has given room to the net foreign position as key indicator to trigger external adjustments. The recent financial turmoil seems to confirm this point. According to European Commission $(2009,2010 b)$, divergence in competitiveness can partially be traced back to benign factors such as Balassa-Samuelson effects, price convergence or cyclical differences. Moreover, as discussed earlier, current account dispersion in a process of progressive monetary and financial integration is a normal outcome. However, there are also less benign drivers of divergence in external performance, like inappropriate responses of wages to productivity shocks, domestic economic imbalances, sluggish productivity performance, accumulation of high private sector debt and the emergence of housing bubbles. The former should be left to the market forces for adjustment while the latter requires some form of policy 
intervention. The distinction between harmful and benign changes in external performance largely depends on the extent to which they are driven by dysfunctional markets or policy mistakes. As pointed out in Blanchard (2007), in a fully flexible economy the swings in competitiveness are temporary but if there exist market distortions - i.e., price and wages rigidities - then, there is a case for welfare improving policy actions. The analysis of determinants of the external disequilibria is an issue of utmost interest, but goes beyond the reach of the present study.

\subsection{Testing for $I(0)$ stationarity on individual time series}

The analysis above is conditional on the maintained assumption that the time series are I(0), an assumption that should be tested. The estimation of the model in (6) with the break points that have been obtained can be used to compute the individual stationarity test in Kwiatkowski et al. (1992) - henceforth, KPSS statistic.

The computation of the individual KPSS statistic permits to get a first analysis of the stochastic properties of the net foreign asset position. The statistics in Panel A in Table 1 offer the computation of the individual KPSS along with the corresponding simulated critical values at the 5 and $10 \%$ level of significance. The results point to the non-rejection of the null hypothesis of $\mathrm{I}(0)$ at the $5 \%$ for six out of eleven cases. The only exceptions are Belgium, France, Italy, Netherlands and Portugal meaning a need for prospective adjustments in order to become solvent. Thus, the evidence points to neither sustainability nor solvency for most countries.

The above inference can be improved if we combine the individual statistics through the definition of panel data statistics. Thus, the literature on non-stationary panel data statistics argues that a better characterization of the stochastic properties of the time series can be obtained if we increase the amount of information when performing the statistical inference. However, some cautions have to be taken when computing these panel-data-based statistics, since some of them rely on the critical assumption of cross-section independence. This assumption is investigated in the next section for our panel data set.

\subsection{The issue of cross-section independence}

In this subsection we test the null hypothesis of cross-section independence against the alternative hypothesis of cross-section dependence using the approach suggested in Pesaran (2013). The test statistic is based on the average of the pair-wise Pearson's correlation coefficients of the residuals obtained from an autoregressive (AR) model that includes dummy variables to capture the structural breaks that have been estimated in the previous section. The weak cross- 
section dependence (WCD) test statistic in Pesaran (2013) converges to the standard normal distribution under the null hypothesis of cross-section independence.

The results in Table 1 show that Pesaran's WCD statistic rejects the null hypothesis of independence, so that cross-section dependence has to be considered when computing the panel data statistics if misleading conclusions are to be avoided. Provided that the WCD statistic does not take a large value, that would indicate that the cross-section dependence driving the units of the panel is not pervasive, i.e., it might not be necessary to model the cross-section dependence using a common factor model - see Pesaran (2013).

\subsection{Panel data tests with cross-section dependence and structural breaks}

The specification estimated above permits the computation of two different panel data stationarity statistics. First, we have applied the approach suggested in Carrion-i-Silvestre et al. (2005) to test the null hypothesis of $\mathrm{I}(0)$ allowing for multiple structural breaks. The OLS estimated residuals from (6) are used to obtain the individual KPSS statistics computed in the previous sections, which in turn can be combined to define two panel stationarity test statistics depending on whether we use a homogeneous long-run variance estimate - the statistic is denoted as $Z(\lambda)_{H O M}$ - or a heterogeneous one - the $Z(\lambda)_{H E T}$ statistic. Since the time series in the panel have been shown to be cross-section dependent, we compute the empirical distribution of the $Z(\lambda)$ statistics by bootstrap following the procedure described in Maddala and $\mathrm{Wu}(1999)$. According to the results in Panel B of Table 1, the null hypothesis of $\mathrm{I}(0)$ cannot be rejected at the $5 \%$ level by either of the statistics.

Second, we have computed the $S_{F}$ panel data stationarity test statistic in Harris et al. (2005), which captures the cross-section dependence through the specification of an approximate common factor model. We present the results of the computation of this test statistic for completeness, although the value of Pesaran's WCD test statistic would indicate that the crosssection dependence among the countries of the panel is not strong. The estimated break points for each country are the ones obtained above, so that this statistic can help to shed light on the stochastic properties of the $n f a$. In order to check the robustness of the $S_{F}$ statistic to the specification of different number of common factors, we have computed the statistic for up to six common factors. The use of panel BIC information criterion in Bai and Ng (2002) always selects the maximum number of factors that is set, whereas the IC2 information criteria in Bai and Ng (2002) indicates that there are no common factors - as mentioned in Bai and Ng (2002), the IC2 information criterion performs well when the number of cross-section units $(N)$ in the panel is not high, as in our case. The results shown in Panel B of Table 1 indicate that the null hypothesis of 
$\mathrm{I}(0)$ cannot be rejected at the $5 \%$ level by the $S_{F}$ statistic, regardless of whether we include six common factors or we do not consider common factors.

In all, we can see that the evidence drawn from the panel data statistics leads to conclude that the $n f a$ panel data set is $\mathrm{I}(0)$. However, this conclusion is reached after the presence of structural breaks have been taken into account, which points to the need of abrupt adjustments of the analyzed countries in order to warrant the solvency of the current account.

\section{Conclusions and policy discussion}

In this paper we have contributed to the literature on external sustainability in several respects. First, we improve previous empirical work on the intertemporal model by analyzing the order of integration of the net foreign assets stock variable by applying non-stationary panel data analysis. Second, we allow for multiple structural breaks and cross-section dependence. Finally, we relate the identification of the structural changes with the literature on current account reversals.

Our results underline the increasing importance of the NFA to GDP ratio as a vital indicator to assess external solvency in the EU as financial integration and cross-section dependence among European markets are also higher. The evidence is in favor of external solvency for the EMU area as a whole. In fact, the evidence obtained indicates that cross-section dependence has to be considered when computing the panel data statistics.

Focusing on the individual statistics, we can see that the null hypothesis of $\mathrm{I}(0)$ cannot be rejected when endogenously determined breaks are accounted for, with six exceptions: Austria and Germany (with persistent surpluses) and Greece, Ireland and Spain (with the opposite position). Finally, Finland has practically regained equilibrium, but with very significant structural breaks and slope changes. The results show an external non-sustainable position for these countries up to 2007, just before the current crisis and, therefore, this evidence was signaling the need of an abrupt adjustment in these economies in order to become solvent or to correct large positive asset positions.

In general, the individual country results point to the fact that policy measures or, otherwise, abrupt readjustments, are still needed to keep the solvency of the current account. The worst cases correspond to the peripheral countries, where the trend continues to be negative with no sign of reversals. Note that an improvement in the current account balance is compatible with a continuous deterioration of the NFA position. The endogenously determined structural breaks serve us to detect those adjustments not only led by the markets, but mostly, promoted by proactive policy measures. Persistent and large current account imbalances have led to quite dramatic changes in the net international positions of the countries considered. Various feedback 
effects from foreign asset stocks may act as stabilizing mechanisms to prevent a continuous increase of the NFA positions, and to ensure an eventual return to the long-run equilibrium. These mechanisms can either come from the market itself or be the result of economic policy measures or agreements (bail-outs, ECB non-conventional measures or, even, haircuts). This evidence would be against a smooth self-regulating capacity of the markets and, therefore, would reject the so-called Lawson doctrine. This calls for an early warning system together with policy rules for enforcement in line with the governance reforms recently taken by the eurozone.

\section{Acknowledgements}

M. Camarero and C. Tamarit, and J.L. Carrion-i-Silvestre gratefully acknowledge the financial support from the MICINN CICYT co-ordinated projects CICYT ECO2011-30260-C03-01 and 03 respectively. Cecilio Tamarit and Mariam Camarero are also members of the Research Group of Excellence on Economic Integration INTECO, funded by Generalitat Valenciana Prometeo action 2009/098. This paper has been developed within the research network SOLVEX, (ECO200906676-E/ECON) funded by MICINN. The authors gratefully acknowledge Gian Maria MilesiFerretti who provided them with the most updated version of his database on external wealth.

\section{References}

Bai, J. and Perron, P. (1998): Estimating and testing linear models with multiple structural changes, Econometrica, 66, 47-78.

Bai, J. and $\mathrm{Ng}$, S. (2002): Determining the number of factors in approximate factor models, Econometrica, 70, 191-221.

Blanchard, O. (2007): Current account deficits in rich countries, IMF Staff Papers, 54, 191-219.

Bohn, H. (2007): Are stationarity and cointegration restrictions really necessary for the intertemporal budget constraint?, Journal of Monetary Economics, 54, 1837-1847.

Brissimis, S.N., Hondroyiannis G., Papazoglou, C., Tsaveas, T.N., Vasardani A.M., (2010): Current account determinants and external sustainability in periods of structural change. Economic Change and Restructuring, Springer, vol. 45(1), pages 71-95,

Brissimis, S.N., Hondroyiannis G., Papazoglou, C., Tsaveas, T.N., Vasardani A.M "The determinants of current account imbalances in the euro area: a panel estimation approach," Economic Change and Restructuring, Springer, vol. 46(3), pages 299-319

Bussiere, M., Fratzscher, M. and Muller, G. J. (2004): Current account dynamics in OECD and EU acceding countries - An intertemporal approach, ECB working paper no. 2281.

Calderón, C., Loayza, N. and Serven, L. (2000): External sustainability. A stock equilibrium perspective, World Bank Policy Research Working Paper no. 2281.

Calderón C. A., Chong A. and Loayza N. V. (2002):. "Determinants of Current Account Deficits in Developing Countries," The B.E. Journal of Macroeconomics, vol. 2(1), 1-33 
Carrion-i-Silvestre, J.L., Del Barrio-Castro, T. and López-Bazo, E. (2005): Breaking the panels: an application to the GDP per capita, Econometrics Journal, 8, 159-175.

Chinn, M., and Prasad, E. (2003): Medium-term determinants of current accounts in industrial and developing countries: An empirical exploration, Journal of International Economics, 59, 4776.

Chortareas, G. E. , Kapetanios, G. and Uctum, M. (2004): An investigation of current account solvency in Latin America using non-linear nonstationary tests, Studies in Nonlinear Dynamics E Econometrics, 8, 1-17.

Corsetti, G. and Roubini, N. (1991): Fiscal deficits, public debt and government solvency: evidence form OECD countries, Journal of the Japanese and International Economies, 5, 354-80.

De Grauwe, P. (2009): The Economics of Monetary Unions, Oxford University Press, 8th ed.

European Commission (2008b): Labour market and wage developments in 2007, European Economy 5/2008.

European Commission (2009): Competitiveness developments within the euro area, Quarterly Report on the Euro area, I, 19-53.

European Commission (2010a): Surveillance of Intra-Euro-Area. Competitiveness and Imbalances. European Economy, 1/2010.

European Commission (2010b): The impact of the global crisis on competitiveness and current account divergences in the euro area, Quarterly Report on the Euro area, vol. 9, n.1.

European Commission (2012): First Alert Mechanism Report On Macroeconomic Imbalances in member states, $\operatorname{COM}(2012) 68$ final, 14.2.2012.

Giavazzi, F. and L. Spaventa, (2010): Why the Current Account Matters in a Monetary Union: Lessons from the Financial Crisis in the Euro Area; CEPR Discussion Paper No. DP8008.

Gourinchas, P. O. and Rey, H. (2007): International Financial Adjustment, Journal of Political Economy, 115, 4.

Harris, D., Leybourne, S. and McCabe, B. (2005): Panel stationarity tests for purchasing power parity with cross-sectional dependence, Journal of Business and Economics Statistics, 23, 395409.

Holmes, M.J. (2006): How Sustainable Are OECD Current Account Balances in the Long Run?, Manchester School, vol. 74(5), 626-643.

Holinski, N., C. Kool, J. Muysken. (2012): Persistent Macroeconomic Imbalances in the Euro Area: Causes and Consequences; Federal Reserve Bank of St. Louis Review January/February

Ingram, J. C. (1959): “State and regional payments mechanism”, Quarterly Journal of Economics, $13,619-632$.

IMF (International Monetary Fund) (2005): Globalization and external imbalances, World Economic Outlook, Chapter III, Washington. 
Isard, P. (2007): Equilibrium exchange rates: Assesment Methodologies, IMF Working Paper, $\mathrm{WP} / 07 / 296$.

Ji, Y. and De Grauwe, P. (2013): The fragility of two monetary regimes: The European Monetary System and the Eurozone, CESifo Working Paper no. 4471.

Kwiatkowski, D., Phillips, P.C.B., Schmidt, P.J., and Shin, Y. (1992): Testing the null hypothesis of stationarity against the alternative of a unit root: How sure are we that economic time series have a unit root, Journal of Econometrics, 54, 159-78.

Lane, P. R. and Milesi-Ferretti, G. M. (2007): The external wealth of nations mark II: Revised and extended estimates of foreign assets and liabilities, 1970-2004, Journal of International Economics, 73, 223-250.

Lee, J., Milesi-Ferretti, G.M., Ostry, J., Prati, A. and Ricci, L. (2008): Exchange rate assessmensts: CGER methodologies, IMF Occasional Paper, No. 261.

Liu, P. and Tanner, E. (1996): International intertemporal solvency in industrialized countries: evidence and implications, Southern Economic Journal, 62, 739-749.

Maddala, G. S. and Wu, S. (1999): A comparative study of unit root tests with panel data and a new simple test, Oxford Bulletin of Economics and Statistics, 61, 631-652.

Mayer, T. (2011): "Euroland's hidden balance of payments crisis", EU Monitor n. 88, Deutsche Bank, Frankfurt.

Milessi-Ferreti, G. M. and Razin, A. (1996): Sustainability of persistent current account deficits, NBER working paper 5467.

Pesaran, M. H. (2013): General diagnostic tests for cross section dependence in panels, Econometric Reviews, forthcoming.

Sinn, H-W (2013): Austerity, growth and inflation: remarks on the Eurozone's unresolved competitiveness problem, The World Economy, 1-13.

Schnabl, G and Zemanek, H. (2011): Inter-temporal Savings, Current Account Dynamics and Asymmetric Shocks in Heterogeneous European Monetary Union, CESifo Working Paper No. 3279 .

Trehan, B. and Walsh, C. (1991): Testing intertemporal budget constraints: theory and applications to US federal budget deficits and current account deficits, Journal of Money, Credit and Banking, 26, 206-223.

$\mathrm{Wu}, \mathrm{J}$. L. (2000): Mean reversion of the current account: evidence from the panel data unit root test, Economics Letters, 17, 423-441.

Wu, J. L., Chen, S. L. and Lee, H. Y. (2001): Are current account deficits sustainable? Evidence from panel cointegration, Economics Letters, 72, 219-224.

Zanghieri, P. (2004): Current Accounts Dynamics in new EU members: Sustainability and Policy Issues, Working Papers 2004-07, CEPII. 
Table 1: Individual and panel stationarity tests with multiple structural breaks

\begin{tabular}{|c|c|c|c|c|c|c|}
\hline \multicolumn{7}{|c|}{ Panel A: Individual test statistics } \\
\hline & KPSS test & $\hat{T}_{b, 1}^{i}$ & $\hat{T}_{b, 2}^{i}$ & $\hat{T}_{b, 3}^{i}$ & $10 \%$ c.v. & $5 \%$ c.v. \\
\hline Austria & $0.073^{* *}$ & 1982 & 2005 & & 0.048 & 0.056 \\
\hline Belgium & 0.038 & 1986 & 1998 & 2005 & 0.030 & 0.034 \\
\hline Finland & $0.102^{* *}$ & 1998 & 2004 & & 0.061 & 0.073 \\
\hline France & 0.053 & 1996 & & & 0.058 & 0.068 \\
\hline Germany & $0.058^{* *}$ & 1987 & 1998 & 2004 & 0.031 & 0.035 \\
\hline Greece & $0.066^{* *}$ & 1984 & 1995 & 2005 & 0.028 & 0.030 \\
\hline Ireland & $0.052 * *$ & 1986 & 1996 & & 0.038 & 0.043 \\
\hline Italy & 0.031 & 2005 & & & 0.086 & 0.105 \\
\hline Netherlands & 0.035 & 1991 & 2002 & & 0.041 & 0.047 \\
\hline Portugal & 0.031 & 1985 & 1993 & & 0.042 & 0.048 \\
\hline Spain & $0.195^{* *}$ & 1996 & & & 0.058 & 0.068 \\
\hline \multicolumn{7}{|c|}{ Panel B: Panel data test statistics } \\
\hline & Test & p-value & & Test & $10 \%$ c.v. & $5 \%$ c.v. \\
\hline Pesaran's WCD test & 3.365 & 0.000 & $Z(\lambda)_{\text {ном }}$ & 7.994 & 17.640 & 20.422 \\
\hline$S_{F}$ (no factors) & 0.290 & 0.386 & $Z(\lambda)_{H E T}$ & 8.395 & 28.587 & 30.826 \\
\hline$S_{F}$ (6 factors) & -0.161 & 0.564 & & & & \\
\hline
\end{tabular}

Note: c.v. denotes critical value, and ** indicates rejection of the null hypothesis of $\mathrm{I}(0)$ at the $5 \%$ level of significance 


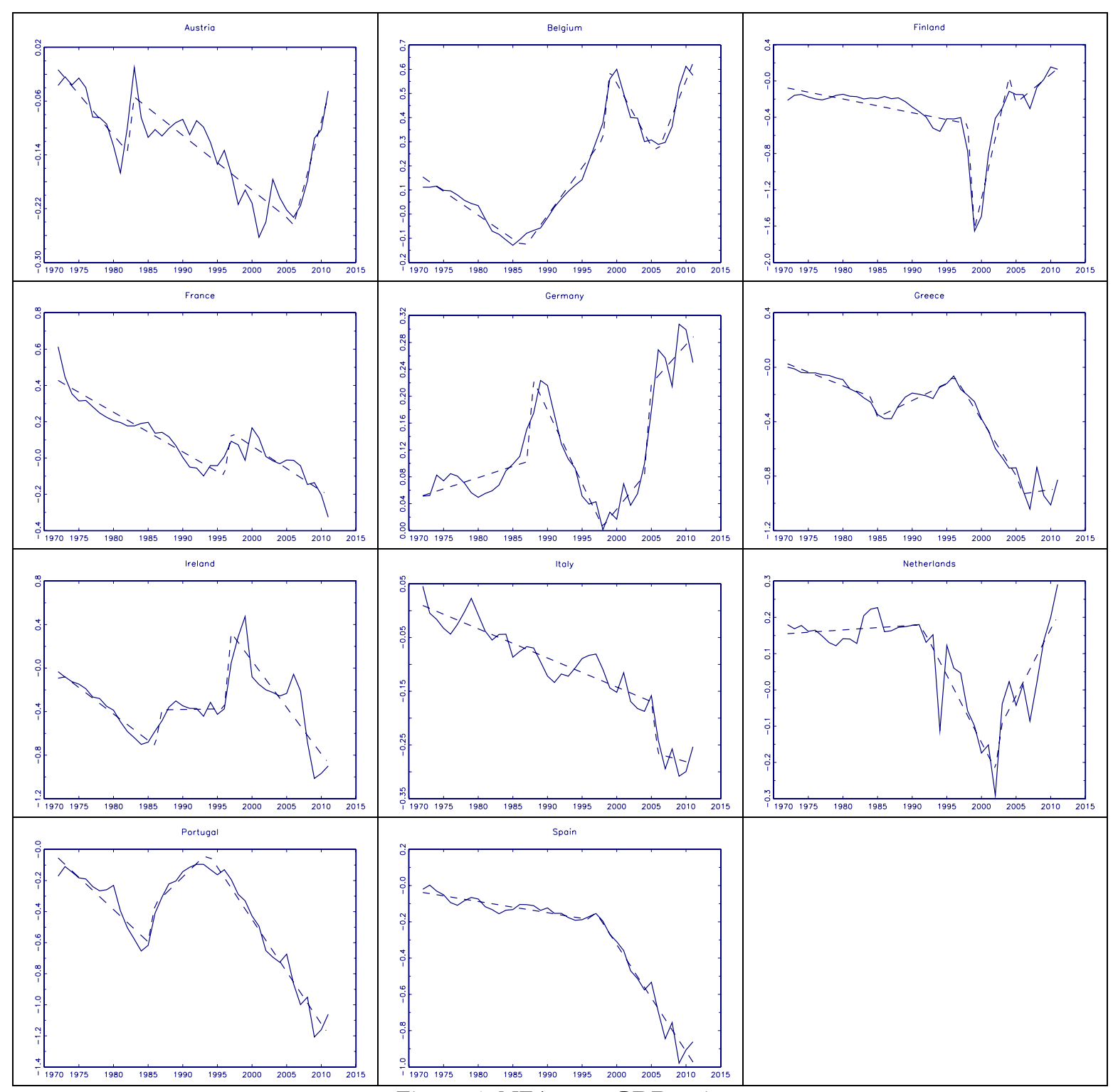

Figure 1: NFA over GDP ratio 